\title{
More supports for unmatched medical students coming soon
}

口 Cite as: CMAJ 2018 February 12;190:E179-80. doi: 10.1503/cmaj.109-5559

Posted on cmajnews.com on Jan. 25, 2018.

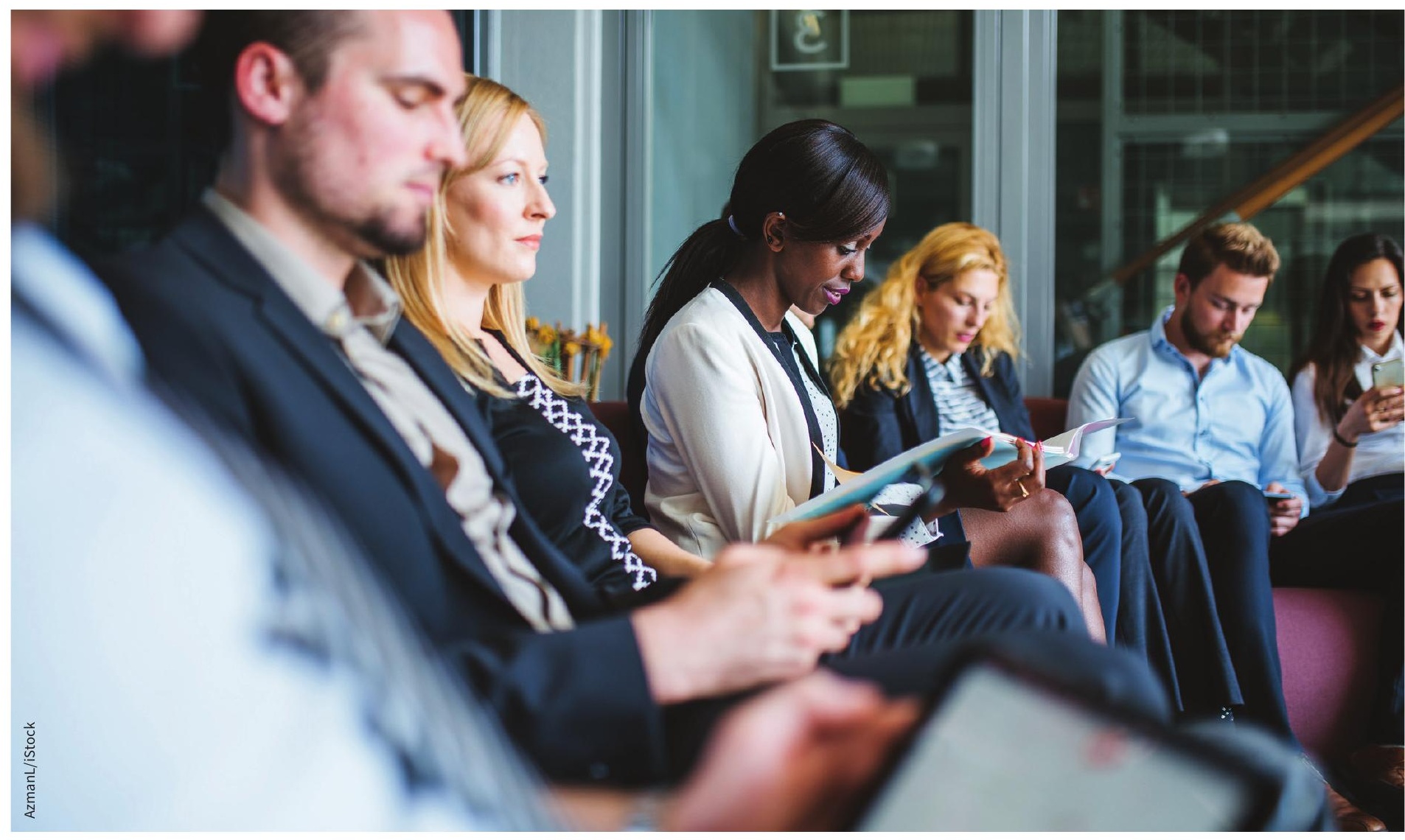

With more medical graduates competing for residency positions this year, faculties are mulling how best to support students who don't match to any spot.

D eans of medicine across Canada are poised to release a strategy for improving supports for medical school graduates who don't match to residency placements.

The number of unmatched medical graduates has been increasing over the past seven years. Last year, 68 students were unable to secure placements after the second round of the match, while 31 dropped out after going unmatched in the first round and 46 remained unmatched from the previous year.
These numbers are expected to increase again this year, as last year's unmatched graduates compete with this year's cohort for the same number of positions.

"This is the most important issue for our students and for medical education," says Dr. Geneviève Moineau, president and CEO of the Association of Faculties of Medicine of Canada (AFMC). Last fall, Canadian deans of medicine committed to create appropriate structures, policies and procedures to support unmatched graduates by October
2018. The AFMC recently completed a consultation on recommendations for action. The results of the consultation and an implementation strategy are now before the AFMC board.

Canadian medical students have been urging their schools to lobby provincial governments to increase the number of residency positions. "Simply, there are not enough seats," explains Sarah Silverberg, the Canadian Federation of Medical Students (CFMS) lead on unmatched graduates. "The 
ideal number is 120 seats per every 100 students, and we are very far off from that ratio."

Last year, there were 101 seats per 100 graduates. Taking into account language requirements, the ratio of seats for Anglophones was less than 1:1. "It's virtually impossible to match every student to a seat because we're working with such little room for flexibility," says Silverberg.

The scarcity of positions has been driven by recent provincial cuts, but so far, "there's been no response from governments to address that issue," she adds.

The CFMS wants medical faculties to prepare students for this new normal, and provide better mental health supports, career counselling and extended clinical opportunities for those who don't match.
Going unmatched can be emotionally, professionally and financially devastating for students, Silverberg explains. In some cases, students find themselves pushed out of their universities and are unable to continue clinical electives to keep up their skills. Graduates who lose student status may also lose health coverage and may have to start repaying their loans. Unmatched graduates also face "shame and stigma, both from the medical community and this real sense of failure that they didn't match and they're spinning their wheels for a year," says Silverberg.

In an open letter in November, CFMS called on medical schools to offer a standardized extension of clerkship and extend student status for all unmatched students. Most medical schools offer some kind of educational program for unmatched students, but the opportunities and supports vary from school to school. "Students often have to be quite self-directed in deciding what to do with that additional year," says Silverberg.

Among other recommendations, CFMS is urging schools to provide better education about "red flags" students should avoid on their applications, give information on the odds of matching to a given specialty, and offer timely feedback to unmatched students about why their applications were rejected.

Medical students also want schools to develop an unmatched student network, and formalize mental health and career counselling supports for unmatched students. "It's important for students to understand there is a light at the end of the tunnel," says Silverberg.

Lauren Vogel, CMAJ 